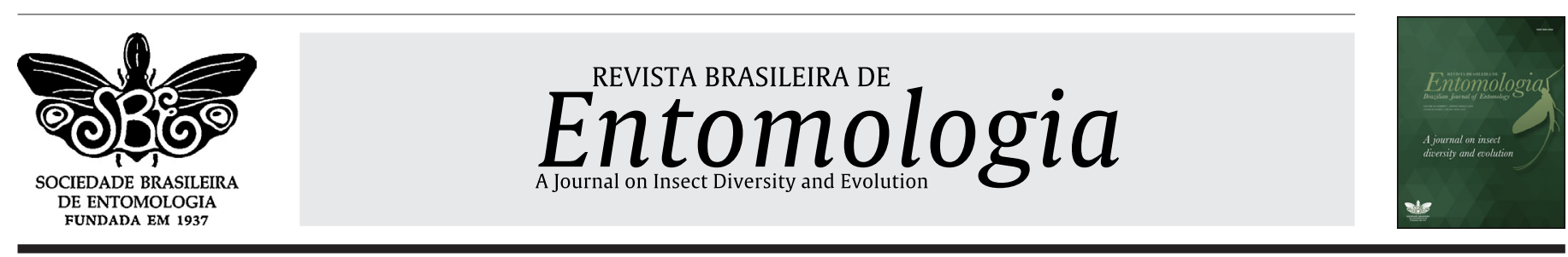

\title{
Cordiluroides Albuquerque (Diptera: Muscidae): new species and key to the Neotropical genus
}

\author{
João Manuel Fogaça ${ }^{1}$ (D), Márcia Souto Courii,3 (D), Angelina Pimentel Vieira-Araújo², \\ Claudio José Barros de Carvalho ${ }^{1,3 *}$ (D)
}

${ }^{1}$ Universidade Federal do Paraná, Departamento de Zoologia, Curitiba, PR, Brasil.

${ }^{2}$ Universidade Federal do Rio de Janeiro, Museu Nacional, Departamento de Entomologia, Rio de Janeiro, RJ, Brasil.

${ }^{3}$ Conselho Nacional de Desenvolvimento Científico e Tecnológico - CNPq, Brasília, DF, Brasil

\section{A R T I C L E I N F O}

Article history:

Received 31 March 2020

Accepted 22 September 2020

Available online 30 October 2020

Associate Editor: Sarah Oliveira

\section{Keywords:}

Atlantic Forest

Coenosiini

Estación Biologica Wayqecha

Parque Nacional do Itatiaia

Scanning Electron Microscope

\begin{abstract}
A B S T R A C T
Here we describe three new species of Cordiluroides Albuquerque, one striking new species from Brazil, Minas Gerais, $C$. albitarsata sp. nov., and two from Peru, Cuzco, $C$. inca sp. nov. and $C$. wayqechensis sp. nov. Additionally, photographs from the types of $C$. listrata Albuquerque, 1954, C. megalopyga Albquerque, 1954 and $C$. insularis (Williston, 1896) are included. With the new species, Cordiluroides is now known from 11 species exclusively distributed in the Neotropical region with records from Bolivia, Brazil, Colombia, Costa Rica, Mexico, Saint Vincent, and Peru. We give an updated identification key to species from the Neotropical region. Finally, we describe for the first time the external morphology and genitalia of the Cordiluroides species using Scanning Electron Microscope (SEM) images.
\end{abstract}

\section{Introduction}

Cordiluroides Albuquerque, 1954, is an exclusively Neotropical genus of Muscidae with records from Bolivia, Brazil, Colombia, Costa Rica, Mexico, Saint Vincent, and Peru (Löwenberg-Neto and de Carvalho, 2013). The genus was proposed by Albuquerque (1954) for three species: $C$. listrata, $C$. megalopyga, and $C$. neotropica, the later one synonymized with C. listrata by Couri and Pamplona (1992). In this study also was proposed a new combination of Cordylura geniculata Macquart, 1851 to Cordiluroides. Later, Pont (1972) proposed two new combinations for the genus: Cordiluroides bicolor (Bigot, 1885) and Cordiluroides insularis (Williston, 1896), originally described in Dialyta Meigen, 1826 and Coenosia Meigen, 1826 respectively. After, Couri and Gonçalves (2002) added a new species $C$. paulistensis to the genus. Finally, Couri et al. (2006) recorded the genus for the first time from Costa Rica and revised the status of Cordiluroides bistriata and $C$. vittifera, removing them from the synonym of $C$. insularis, so that the genus has now eight valid species.

Species of the genus can be easy distinguished by the high insertion of antenna, above middle of the eye, the presence of only one pair of

\footnotetext{
* Corresponding author:

E-mail: cjbcarva@gmail.com (C. J. B. de Carvalho)
}

postsutural intra-alar setae, lower calypter transverse, and abdomen elongated (Albuquerque, 1954). There are three identification keys to the genus: Couri and Pamplona (1992) and Couri and de Carvalho (2002) for the Neotropical species, and Couri et al. (2006) for the Costa Rica species. There is no information about the biology and immature stages.

Here we describe one striking new species from Minas Gerais, Brazil and two new species collected from Peru. We also provide photos from the type material of $C$. insularis Williston, 1896, C. listrata Albuquerque, 1954, and C. megalopyga Albuquerque, 1954. An updated key to the Neotropical species of Cordiluroides also furnished. Herein, we describe for the first time the external morphology and genitalia of the Cordiluroides species using Scanning Electron Microscope (SEM) images.

\section{Material}

This study was mostly based on Cordiluroides specimens from Wayqecha Cloud Forest Biological Station (Cuzco, Peru), collected by Malaise trap in June 2012, which are deposited in the National Museum of Natural History (USNM) and the Padre Jesus Santiago Moure 
entomological collection, Universidade Federal do Paraná, Curitiba, Brazil (DZUP). The material from Parque Nacional do Itatiaia (Rio de Janeiro and Minas Gerais states, Brazil) was collected using Malaise traps placed on "Brejo da Lapa" area, located in the highest part of the park, as part of the project "Conhecer para proteger: Medindo a riqueza de insetos do Parque Nacional do Itatiaia - BIOTA-FAPERJ" coordinated by Marcela Monné (Museu Nacional, UFRJ). This material was identified based on the available Neotropical species keys and prepared at the Diptera laboratory of Museu Nacional, Universidade Federal do Rio de Janeiro (MNRJ/UFRJ).

Besides these material freshly collected, we also analyzed material type from C. insularis Williston, 1896 (The Natural History Museum, London, United Kingdom -BMNH),C. listrata Albuquerque, 1954 (MNRJ), and C. megalopyga Albuquerque, 1954 (MNRJ).

\section{Dissections and terminology}

Pinned dry specimens were examined under the stereomicroscope and the terminalia were examined after being removed from the abdomen, cleared with cold potassium hydroxide (KOH) $10 \%$ for 24 hours, then transferred to acetic acid, after being dehydrated in 70\% alcohol and then placed in glycerin. The terminalia were dissected, analyzed and illustrated under the optical microscope with the help of a camera lucida. After examination, the terminalia were placed in glass vials that were fixed to the original pinned specimen.

The terminology for the external morphology and terminalia followed Cumming and Wood (2017). The following abbreviations were used: $a$ - anterior surface, a kepst $s$ - anterior katepisternal seta, acr $s$ - acrostichal seta, ad - anterodorsal surface,anepst - anepisternum, $a v$ - anteroventral surface, $b$ pprn $s$ - basal postpronotal seta, $b$ sctl $s$-basal scutellar seta, $d$ - dorsal surface, $d c s$ - dorsocentral seta, ial $s$-intra-alar seta, $n p l$ - notopleuron, $p$ - posterior surface, $p a l s$ postalar seta, $p d$ - posterodorsal surface, $p v$ - posteroventral surface, sctl $s$-scutellar seta, spal $s$ - supra-alar seta, $v$ - ventral surface.

\section{Images}

The entire specimens or extracted male genitalia were used in Scanning Electron Microscope (SEM). For the photographs, the entire specimens or male genitalia were dehydrated in a graded series of alcohol, critical-point dried and sputter-coated with gold. Photographs were taken using a JEOL JSM 6360-LV at Centro de Microscopia Eletrônica, Universidade Federal do Paraná, Curitiba, Paraná, Brazil.

Photographs of the adult habitus of new species from Peru and Brazil were stacked using an auto-montage setup acquired at Laboratório de Sistemática e Bioecologia de Coleoptera (UFPR), and a Leica M205 C, version v 4.8.0 at Museu Nacional, Universidade Federal do Rio de Janeiro (UFRJ), respectively. Photographs of the type material were stacked using an auto-montage setup acquired at Museu Nacional, Universidade Federal do Rio de Janeiro, Rio de Janeiro and Natural History Museum, London.

\section{Results}

\section{Taxonomy}

Key to species (Modified from Couri and de Carvalho, 2002 and Couri et al., 2006)

1 Apical scutellar seta very reduced or absent (Fig. 1e and 2e); anterior supra-alar present or absent
- Apical scutellar seta well developed (Fig. 3c); anterior supraalar present ... 5

2 (1) Gena and postgena in male and postgena in female with white setae (beard) (Fig. 4c), fore tarsus in male elongated, tarsomeres 2-5 flattened and white (Brazil) (Fig. 4a)

C. albitarsata sp. nov. (Figs. 4 and 5)

- Gena and postgena without white setae (beard) (Fig. 1b and 6b); male fore tarsus elongated and flattened

... 3

3 (2) Frons, parafacial with grey pruinosity; abdominal tergites all dark brown or with silvery parts (Fig. 4a) 4

- Frons, parafacial yellowish pruinosity; abdominal tergites 1-3 with yellow parts (Fig. 2a)

C. wayqechensis sp. nov. (Figs. 2, 7, 8 and 9)

4 (3) All surfaces of hind femur yellow; abdomen all dark brown C. inca sp. nov. (Figs. 1, 10 and 11)

- Anterior surface of hind femur silvery pruinose; Abdomen dark brown with lateral parts silvery pruinose

C. paulistensis Couri \& Gonçalves, 2002

5 (1) General coloration reddish; palpus light brown; coxa with blackish cloud near apex (México) ............ C. bicolor (Bigot, 1885)

- General coloration brown; palpus dark brown to black; coxa without blackish cloud near apex

... 6

6 (5) Arista, on basal half, with short cilia (cilia longer than the basal diameter of arista) and bare on apical half (Brazil)

C. geniculata (Macquart, 1851)

- Arista with cilia not as above
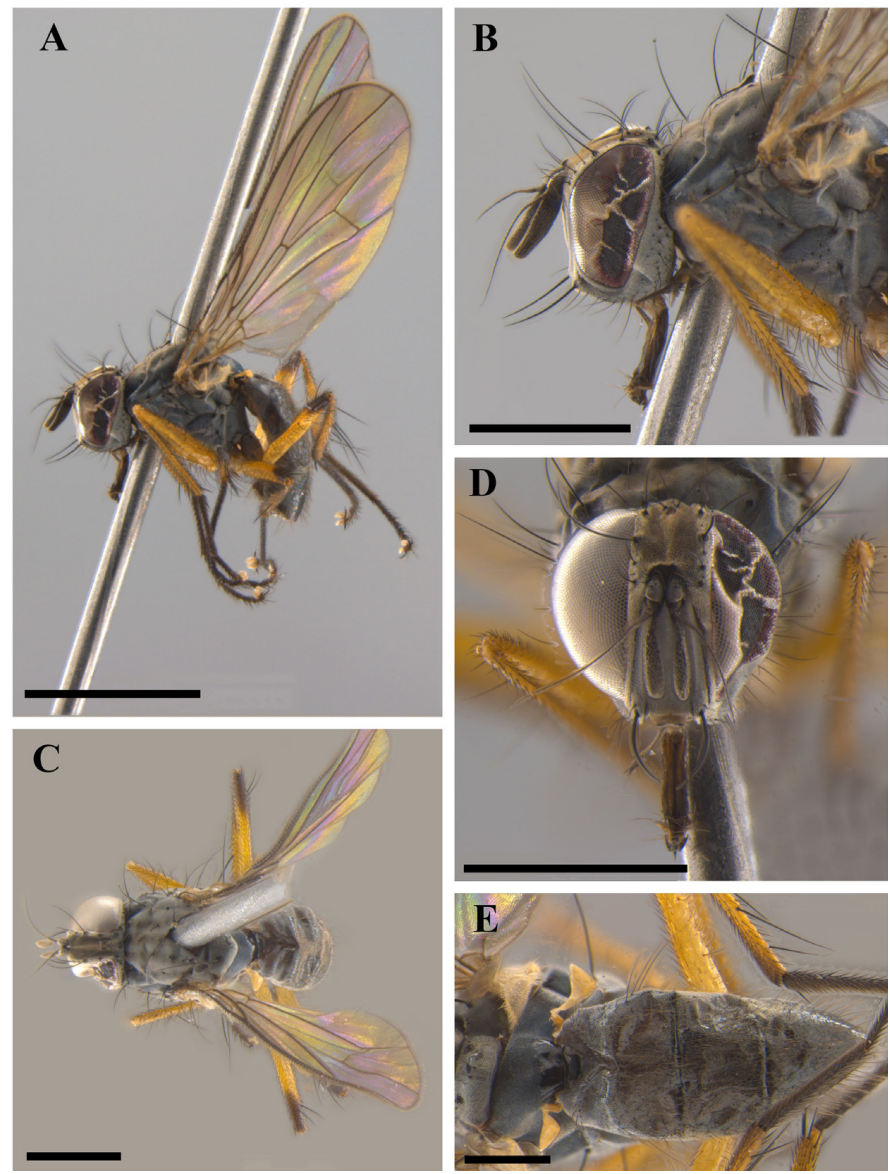

Figure 1 Cordiluroides inca new species. Holotype. Male. a) Habitus, lateral view; b) Head, lateral view; c) Habitus, dorsal view; d) Head, anterior view; e) Abdomen, dorsa view. Scale bars $a=2 \mathrm{~mm} ; \mathrm{b}-\mathrm{d}=1 \mathrm{~mm} ; \mathrm{e}=0.5 \mathrm{~mm}$. 
7 (6) Abdomen of male very elongated, tergites $1+2$ and 3 translucent yellow and with a median dorsal triangular brown cloud; tergites 4 and 5 brown, sometimes tergite 4 also translucent yellow at base; abdomen of female not elongated, brown, with lateral yellow areas on tergites $1+2$ and 3 and grey pruinose on tergites 4 and 5; wings
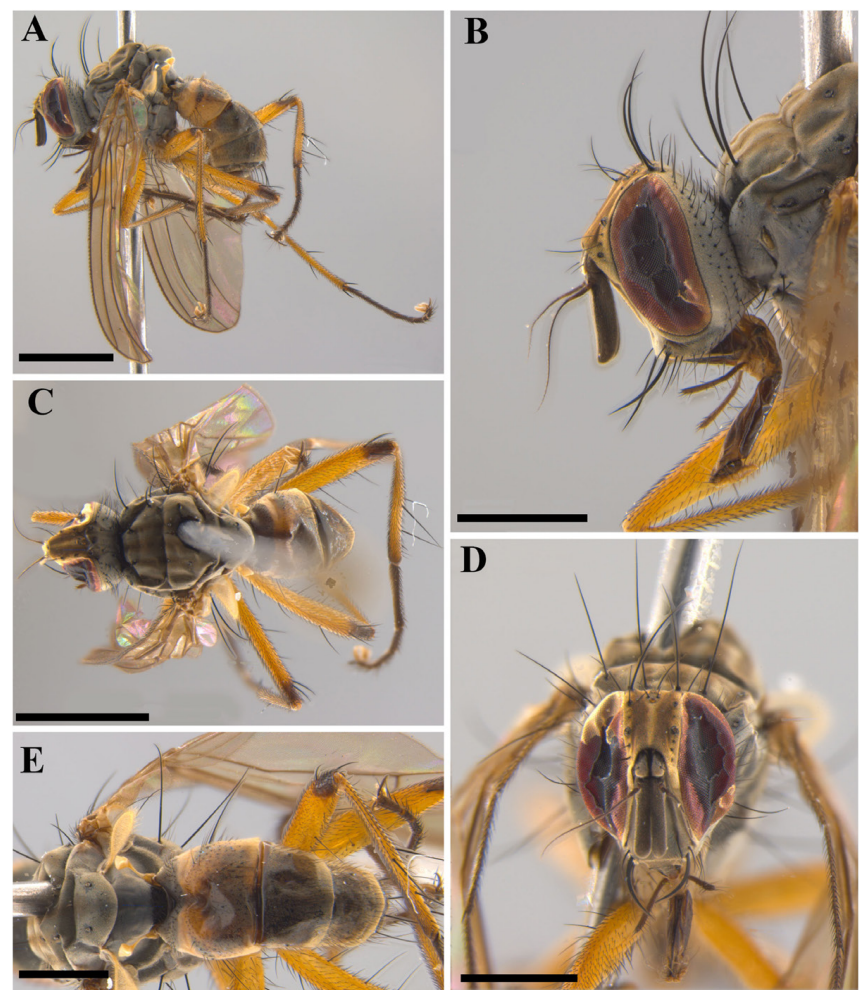

Figure 2 Cordiluroides wayqechensis new species. Holotype. Male. a) Habitus, lateral view; b) Head, lateral view; c) Habitus, dorsal view; d) Head, anterior view; e) Abdomen, dorsal view. Scale bars $a=2 \mathrm{~mm} ; b=1 \mathrm{~mm} ; c=2 \mathrm{~mm}$; $d$ and $e=1 \mathrm{~mm}$.
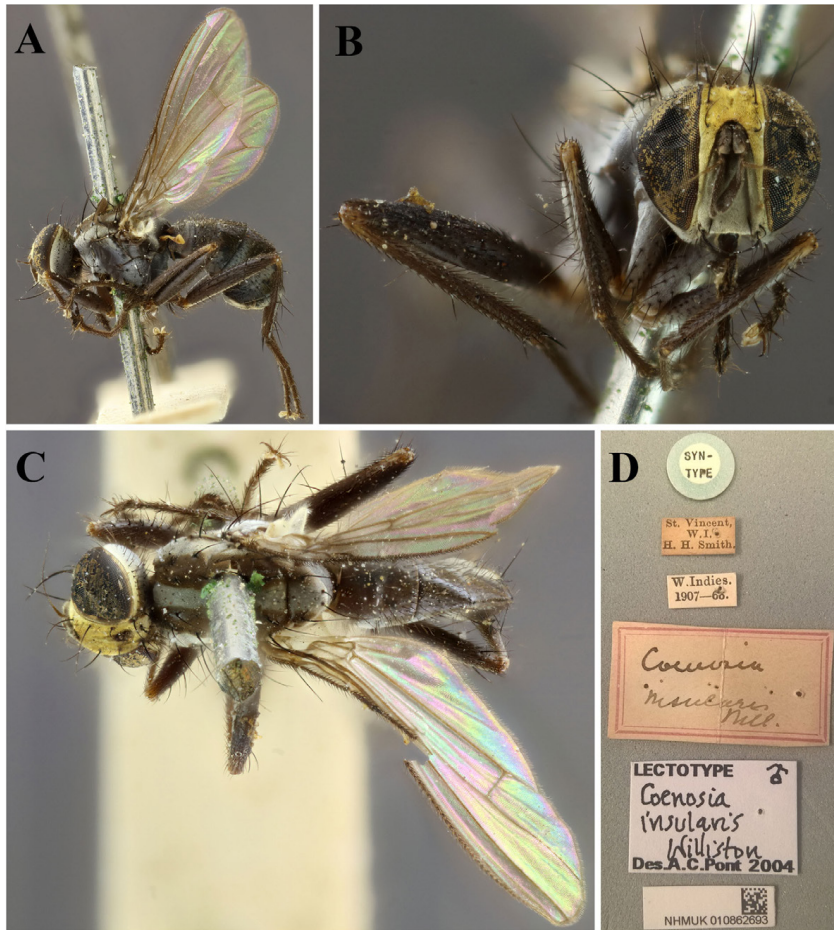

Figure 3 Cordiluroides insulares. Syntype. (BMNH). Male. a) Habitus, lateral view; b) Head, anterior view; c) Habitus, dorsal view; d) Labels. smoky, especially on apical third (Mexico, Peru, Costa Rica) ......... C. bistriata (van der Wulp, 1896)

- Abdomen of male and female not as described above; wings smoky or hyaline 8

8 (7) Ocellar setae absent, legs yellow, with apical half of femora and tarsi light brown; male terminalia prominent (Brazil)

C. megalopyga Albuquerque, 1954 (Fig. 6)

- Ocellar setae present, legs dark brown; male: terminalia not prominent

9 (8) Frons and parafacial bearing strong yellowish pruinosity; abdomen with a median brown vitta and a brown spot on lower half of each segment; wings smoky (Mexico, St. Vincent Is., Colombia, Peru, Bolivia) C. insularis (Williston, 1896) (Fig. 3)

- Frons and parafacial covered with some yellowish pruinosity; abdomen brown with light brown to yellow clouds on tergites, some males with tergites $1+2$ and 3 with yellow marks; wings hyaline (Brazil, Costa Rica)

C. listrata Albuquerque, 1954 (Fig. 12)

\section{Cordiluroides albitarsata sp. nov.}

(Figs. 4 and 5)

urn:Isid:zoobank.org:act:579D3D91-E7AA-493B-9AEB-8688B404166F

Material. Holotype: Male. PNI [Parque Nacional do Itatiaia] - M1A / DATA: 02. x. 2015 - 03.xi.2015 / BIOTA-FAPERJ / DIPTERA / BRACHYCERA
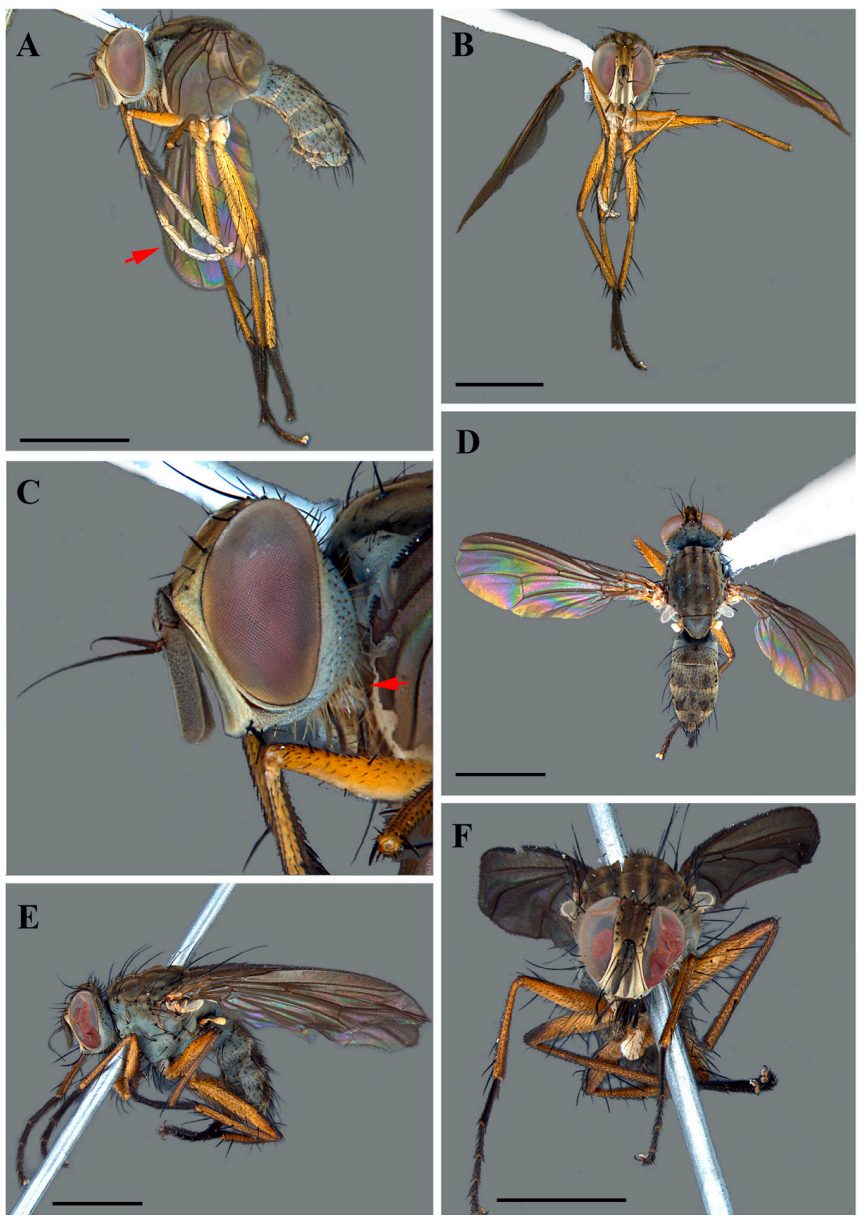

Figure 4 Cordiluroides albitarsata new species. Holotype. Male. a) Habitus, lateral view b) Habitus, anterior view; c) Head detail, lateral view; d) Habitus, dorsal view. Paratype. Female. e) Habitus, lateral view; f) Habitus, anterior view. red arrow = a) tarsomeres 2-5 flattened and white; c) white setae (beard). Scale bars $2 \mathrm{~mm}$. 
/ BRASIL: MG. Itamonte, PNI, Setor Brejo / da Lapa, Brejo da Lapa, PNIM1A / coord: 22ํ2'32,40"S, 444'14.04”W, / 2142 m a. s. 1. (MNRJ).

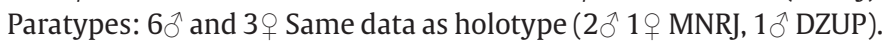

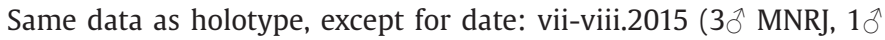
DZUP). X-xi.2015 (1 9 MNRJ).

Diagnosis. The presence of white setae (beard) in the gena and postgena in male (Fig. 4c) and female, fore tarsus with tarsomeres 2-5 flattened and white in male (Fig. 4a) easily distinguish Cordiluroides albitarsata sp. nov. from the other Cordiluroides. Ground color brown with grey pollinosity. Head (Fig. 4a-c and f): Frons brown with a discrete golden pruinosity in center in male and more homogeneous dark brown in female; fronto-orbital plate, face and gena silver pruinose; gena and postgena in male and only postgena in female with white setae (beard); antennae and arista brown, apex of pedicel lighter in some specimens; palpus dark brown. Thorax (Fig. 4d-e): Scutum with 5 brown vittae, a little larger in female. Upper and lower calypters white; halter yellow. Wing: Infuscated (Fig. 4d). Legs: All coxae yellow with white pollinosity, fore femur yellow, mid and hind femora yellow with apical fifth brown, all tibia yellow, all tarsi dark brown, except fore tarsus in male with tarsomere 1 dark brown, except on tip, tarsomere 2 white, with a brown area at base, tarsomeres 3-5 white (Fig. 4a); pulvilli light brown, claws black, ligther at base. Abdomen: With a brown middle stripe and lateral brown clouds in all tergites.

Length. Male: body: 3.90 -3.95 mm; wing: $4.2 \mathrm{~mm}$.

Head. Interocular space about one-third of head-width at the level of anterior

ocellus. Four pairs of frontal setae, the two lower ones short and the two superior ones long and backwards directed; inner vertical

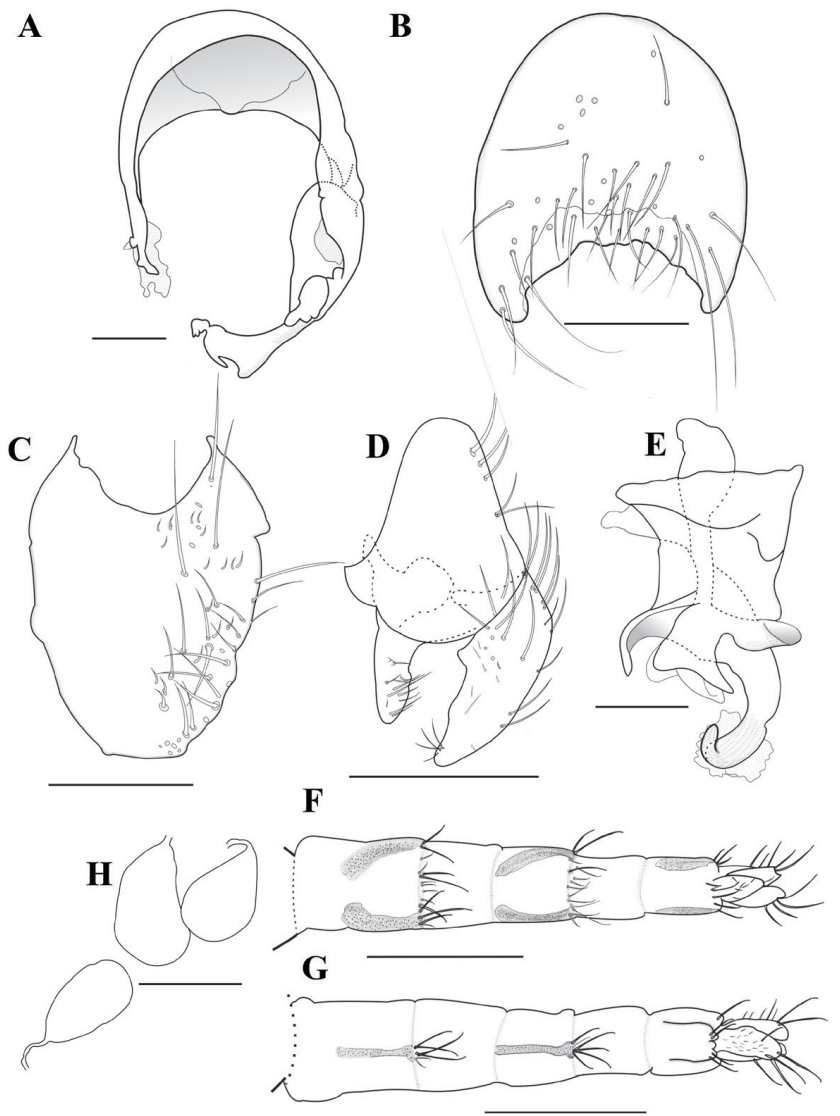

Figure 5 Cordiluroides albitarsata new species. Paratype. Male. a) syntergosternite 7+8, dorsal view; b) Sternite 5, dorsal view; c) Cercus, posterior view; d) Terminalia, lateral view; e) Complex phallic, lateral view. Paratype. Female. f) ovipositor, dorsal view; g) ovipositor, ventral view; $h$ ) Spermathecae. Scale bars a-g=0.1 $\mathrm{mm} ; \mathrm{h}=0,05 \mathrm{~mm}$. seta long; ocellar setae very short; antennae inserted a little above middle of eyes; pedicel reaching oral margin; arista short pubescent. Gena narrow. Vibrissa strong and long. Proboscis with developed teeth.

Thorax chaetotaxy. acr $s$ in a row of short cilia; $d c s 1+3$, all long; ial s 1+1, spal s 1+1; pal s 1; b pprn s 1; npl 2; anepst 4-5; a kepst s $1+1+1$. $b$ sctl $s$ longer than the $s c t l s$ length. Sternite 1 bare.

Legs. Fore femur with a row of long and sparse setae on $p d$ and $p v$ surfaces; fore tibia with one long median $p$ setae, one preapical $d$ and two apicals, one $p$ and one $p v$. Mid femur with two ad setae on middle third, 3-4 long and sparse $v$ setae, posterior surface with two preapical setae; mid tibia with one long median ad setae, one long median $p d$, one long preapical $d$ and one apical $a d$; hind femur with a sparse $a d$ row with about six setae, av surface with four sparse setae, preapical setae on $d$, ad and $p d$ surfaces; hind tibia with one long median ad seta, one long $d$ on apical-third, one $a v$ on apical-third, one preapical $a d$ and one apical $v$ strong.

Wing. All veins bare, except costal.

Abdomen. Elongated. Tergite 1 with three lateral setae on each side, tergites 2-3 with one pair of lateral setae, tergite 4 with two apical setae and one lateral, tergite 5 with a discal and a marginal row of setae. Tergite 6 asymmetric (Fig. 5a), sternite 5 "U" Shaped (Fig. 5b).

Terminalia. Surstyli shorter than cercal plate and rounded in the apex (Fig. 5d). Cercus longer than wide, wider basally than apically, covered with median to long setae (Fig. 5c). Hypandrium moderate to long tubular (Fig. 5e).

Female. Similar to male in most aspects, except for white beard in the gena and postgena not so dense as in male; abdomen not elongated. Terminalia: Ovipositor long with microtrichia along its whole length, tergites fine, cerci long (Fig. $5 \mathrm{f}$ and $5 \mathrm{~g}$ ). Three rounded spermathecae (Fig. 5h).
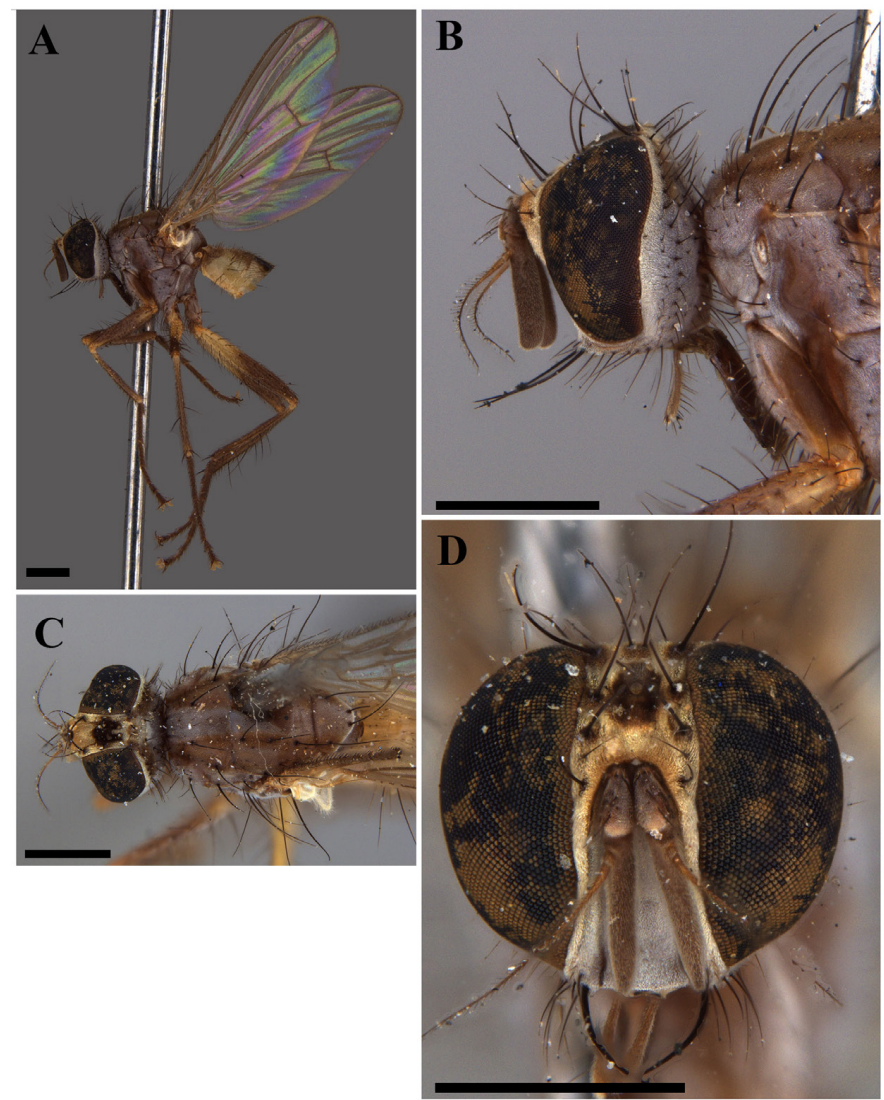

Figure 6 Cordiluroides megalopyga. Holotype. (MNRJ). Male. a) Habitus, lateral view b) Head, lateral view; c) Habitus, dorsal view; d) Head, anterior view. Scale $1 \mathrm{~mm}$. 

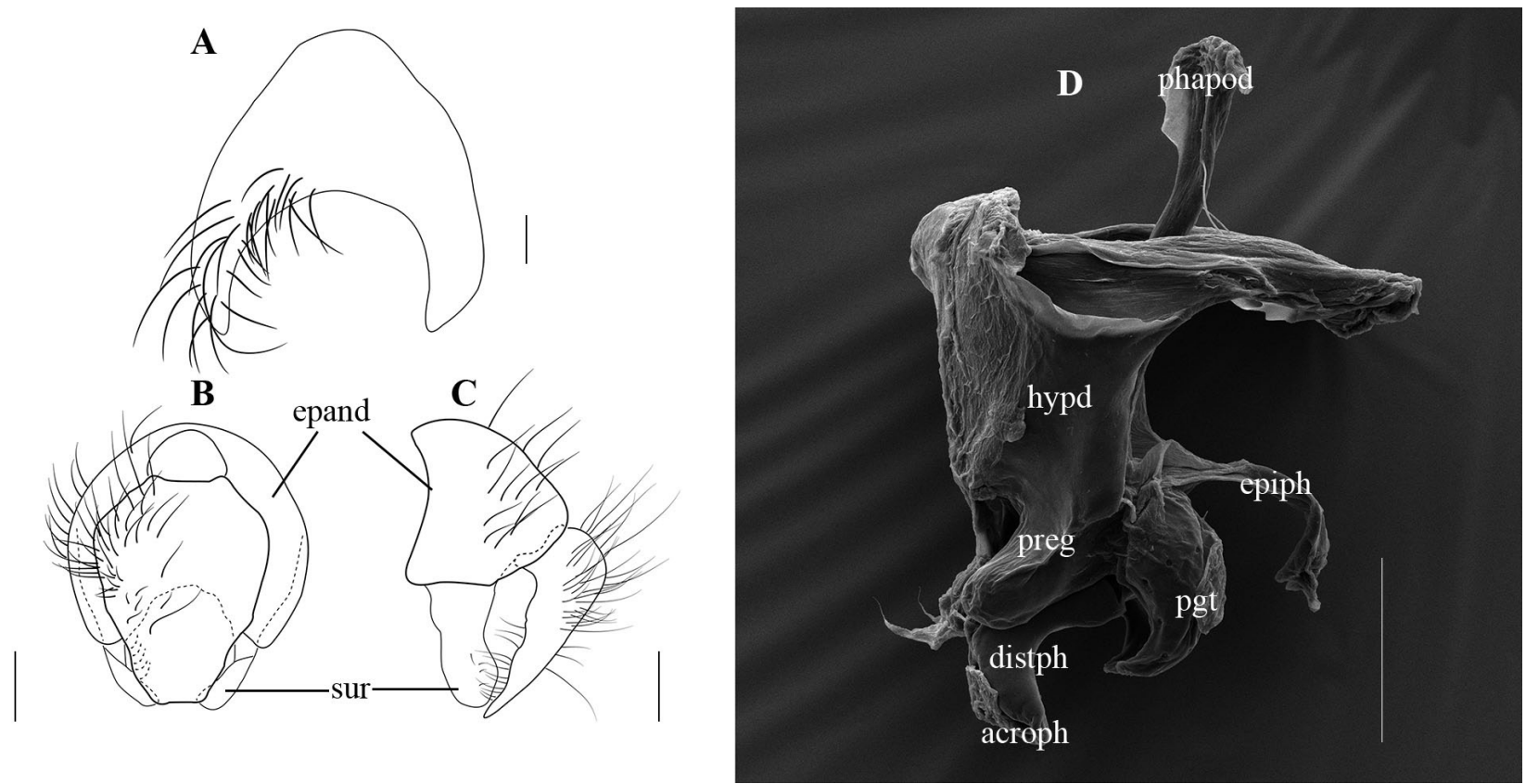

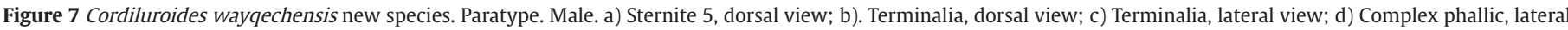

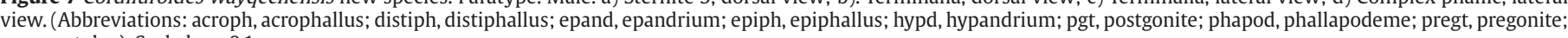
sur, surstylus). Scale bars $0.1 \mathrm{~mm}$.
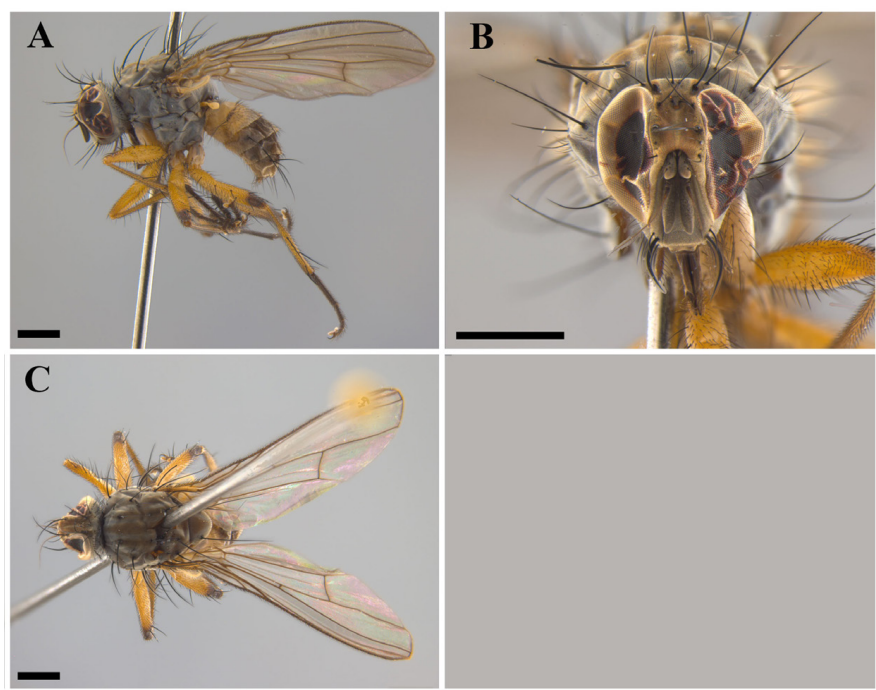

Figure 8 Cordiluroides wayqechensis new species. Paratype. Female. a) Habitus, lateral view; b) Head, anterior view; c) Habitus, dorsal view. a-c=1 mm.

Etymology. The specific epithet, albitarsata, refers to the white tarsi in male.

Distribution. BRAZIL, Minas Gerais: Parque Nacional do Itatiaia.

\section{Cordiluroides inca sp. nov.}

(Figs. 1, 10 and 11)

urn:Isid:zoobank.org:act:0104A390-04B2-4AC5-97E6-0F63BBAB11AA

Material. Holotype: Male. "Peru: Cuzco: Est. Biol. | Wayqecha jct. Trochas \Schefflera Picaflor, \Malaise trap, WP 583, \13. 17385 S \71. $58808 \backslash$ W 2905m, 1-12 Jun \2012, A. L. Norrbom, B. \D. Sutton, B. Luz Puma $\mid \&$ C. Quispe (white printed label)" (USNM). Paratypes: $2 \precsim$. Same data as holotype ( $1 \precsim$ DZUP/ $1 \precsim$ USNM).
Diagnosis. Apical scutellar seta reduced, yellow legs, brown tarsi and abdomen entirely dark brown easily distinguish Cordiluroides inca sp. nov. from the other Cordiluroides. Ground color brown with grey pollinosity (Fig. 1a). Head (Fig. 1d): Frons brown; face, fronto-orbital plate and gena silvery pruinose; antenna and arista dark brown; palpus brown. Thorax (Fig. 1c): Scutum with 5 light brown vittae. Calypter whitish; halter yellow. Wing: Slightly infuscate. Legs: Fore coxa yellow, mid and hind coxae grey pruinose; fore femur yellow, mid and hind femora yellow with apical third brown; tibiae yellow; tarsi brown; pulvilli yellowish-white; claws black. Abdomen: Male (Fig. 1e) with all tergites brown with grey lateral margin.

Length. Male: body: $2.0 \mathrm{~mm} \mathrm{~mm}$; wing: $2.3 \mathrm{~mm}$.

Head. Interocular space about one-third of head-width at level of anterior ocellus. Eyes sparsely ciliated (Fig. 10c). Four pairs of frontal setae with different lengths; one pair of long reclinate orbital setae; ocellar setae long (Fig. 10b), similar in length to the reclinate orbital. Antennae inserted a little above middle of eyes; flagellomere about 3 times as long as pedicel; arista short pubescent (Fig. 10c-d). Gena narrow. Vibrissa strong and long (Fig. 10b). Proboscis with developed teeth.

Thorax chaetotaxy (Figs. 1c and 10e). acr $s 1+2$; dc $s 1+3$, all long; ial s 1+2, the second longer; spals $1+1$; pal s 1 ; b pprn $s 1 ;$ npl2; anepst 6; a kepst $s 1+1+1$. b sctl $s$ longer than the $s c t l s$ length. Sternite 1 bare.

Legs. Fore femur with a row of sparse setae on $p d$ and $p v$. Fore tibia with one long median $p$ seta; one $d, p$ preapical seta; one $p v$ apical seta, these three shorts. All pulvilli and claws developed. Mid femur with 4 long sparse $p v$ setae; $p$ with two preapical setae. Mid tibia with a submedian $a$ to $a v$ seta; one $d, p, v$ and $p v$ preapical seta, the $v$ is larger than the others. Hind femur with 4 long apical ad setae; one apical $d, p d$ seta and $p v$ with 3 long, thin and sparse setae. Hind tibia with one long median $p d$, ad seta; one long submedian $d$ seta; one $a d, a v$ preapical seta.

Wing (Figs. 1a and 10f). All veins bare, except costal.

Abdomen (Fig. 1a and 1e). Elongated. All tergites with very small setae. Sternite 5 quadrate, with setae concentrated on apical half (Fig. 11a).

Terminalia (Fig. 11a-d). Surstylus well-developed, longer than cercus, enlarged on lateral view (Fig. 11c). Cercus longer than wide, 


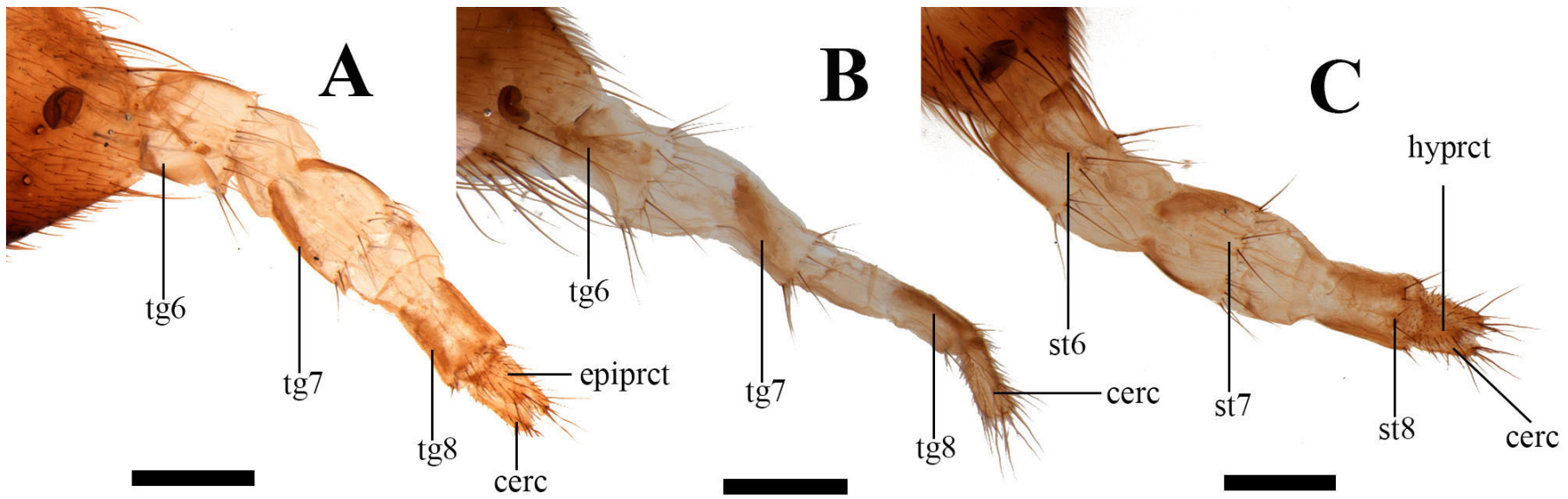

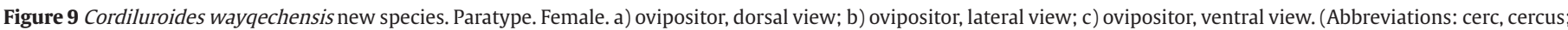
epiprct, epiproct; hyprct, hypoproct; st, sternite; $\mathrm{tg}$, tergite; ). Scale bars $0.1 \mathrm{~mm}$.
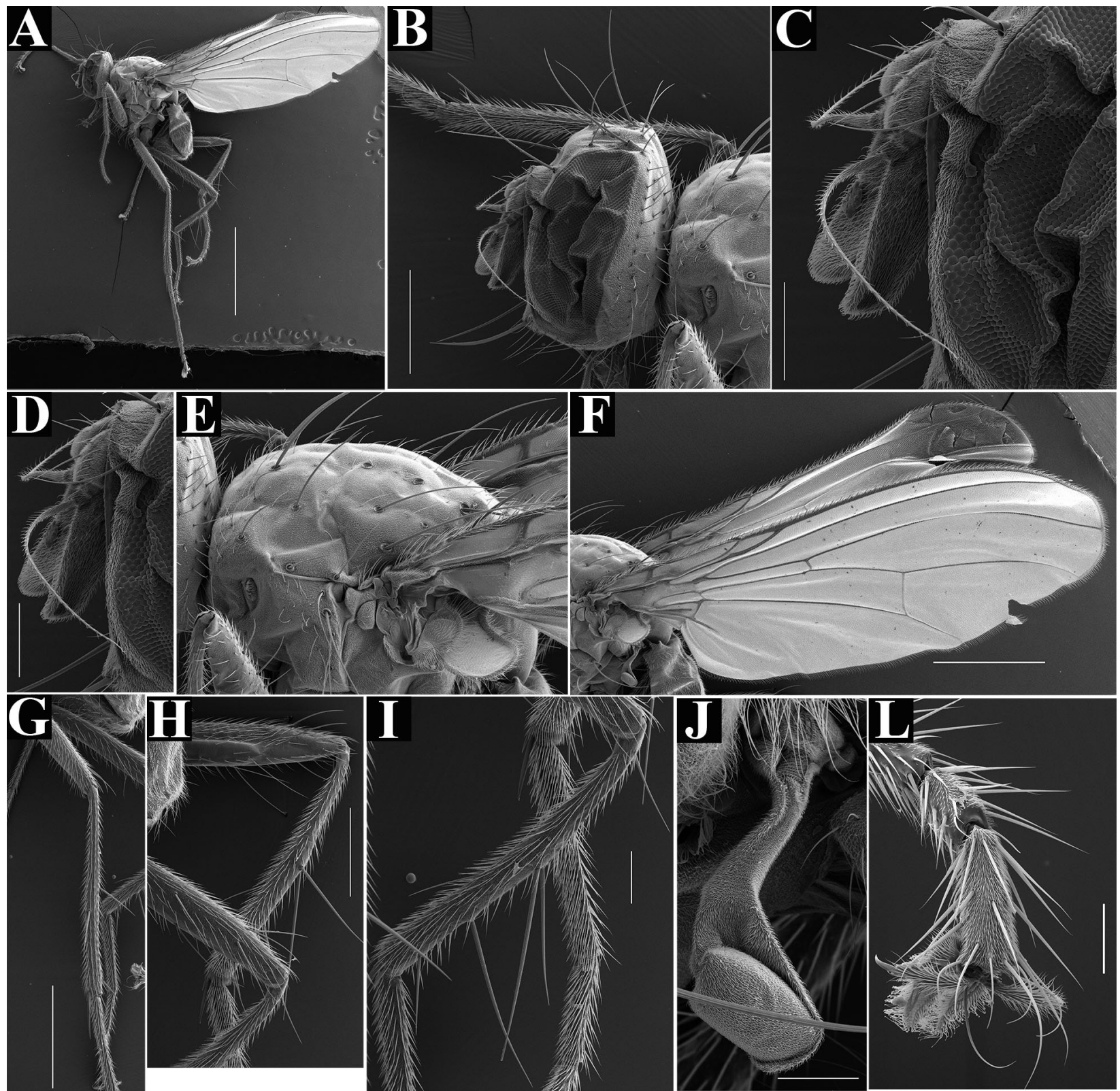

Figure 10 Cordiluroides inca new species. Paratype. Male. a) Habitus, lateral view; b) Head, lateral view; c) Antenna, lateral view; d) Antenna detail, lateral view; e) Thorax, lateral view; f) Wing, lateral view; g) Mid leg, lateral view; h) Hind tibia, lateral view; i) Posterior tibia, lateral view; j) Halter, lateral view; l) Tarsi, dorsal view. Scale bars a=2mm; b, e, $\mathrm{h}=500 \mu \mathrm{m} ; \mathrm{c}, \mathrm{d}, \mathrm{i}=200 \mu \mathrm{m} ; \mathrm{f}, \mathrm{g}, \mathrm{h}=1 \mathrm{~mm} ; \mathrm{j}, \mathrm{l}=100 \mu \mathrm{m}$. 
wider basally than apically, covered with median to long setae (Fig. 11b). Hypandrium moderate to long tubular (Fig. 11d). Phallic complex (Fig. 11d): phallapodeme enlarged apex; epiphallus curved apex; praegonite well developed with a few setulae; postgonite long, curved with a few setulae; distiphallus short and sclerotized, acrophallus membranous.

Female. Unknown.

Etymology. The specific epithet, inca, refers to the pre-Colombian South American peopling.

Distribution. PERU, Cuzco: Est. Biol. Wayqecha.

\section{Cordiluroides wayqechensis sp. nov.}

(Figs. 2, 7, 8 and 9)

urn:Isid:zoobank.org:act:E50AFF70-2715-4D21-BCC7-10D549E63764

Material. Holotype: Male. "Peru: Cuzco: Est. Biol. | Wayqecha jct. Trochas \Schefflera \& Picaflor, | Malaise trap, WP 583, | 13. 17385 S | 71. 58808 \W 2905m, 1-12 Jun \2012, A. L. Norrbom, B. \D. Sutton, B. Luz Puma $\mid \&$ C. Quispe (white printed label)" (USNM). Paratypes: $16{ }^{\AA}$

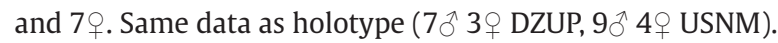

Diagnosis. The apical scutellar seta reduced, frons and parafacial with yellowish pruinosity; yellow legs and abdomen with yellow parts easily distinguish Cordiluroides wayqechensis sp. nov. from the other Cordiluroides. Ground color brown with grey pollinosity (Fig. 2a). Head (Fig. 2d): Frons brown; face, fronto-orbital plate and gena silvery; antenna and arista brown, apex of pedicel lighter; palpus brown. Thorax (Fig. 2c): Scutum with 5 light brown vittae. Calypter infuscated; halter yellow. Wing slightly infuscated. Legs: Fore coxa yellow; mid and hind coxae slightly grey pruinose; fore femur yellow; mid and hind femora yellow with apical third brown; tibiae yellow; tarsi brown; pulvilli yellowish-white; claws black. Abdomen of male (Fig. 2e) with tergites $1+2$ yellow with grey areas, $3+4$ yellow on lateral area and 5 wholly brown.

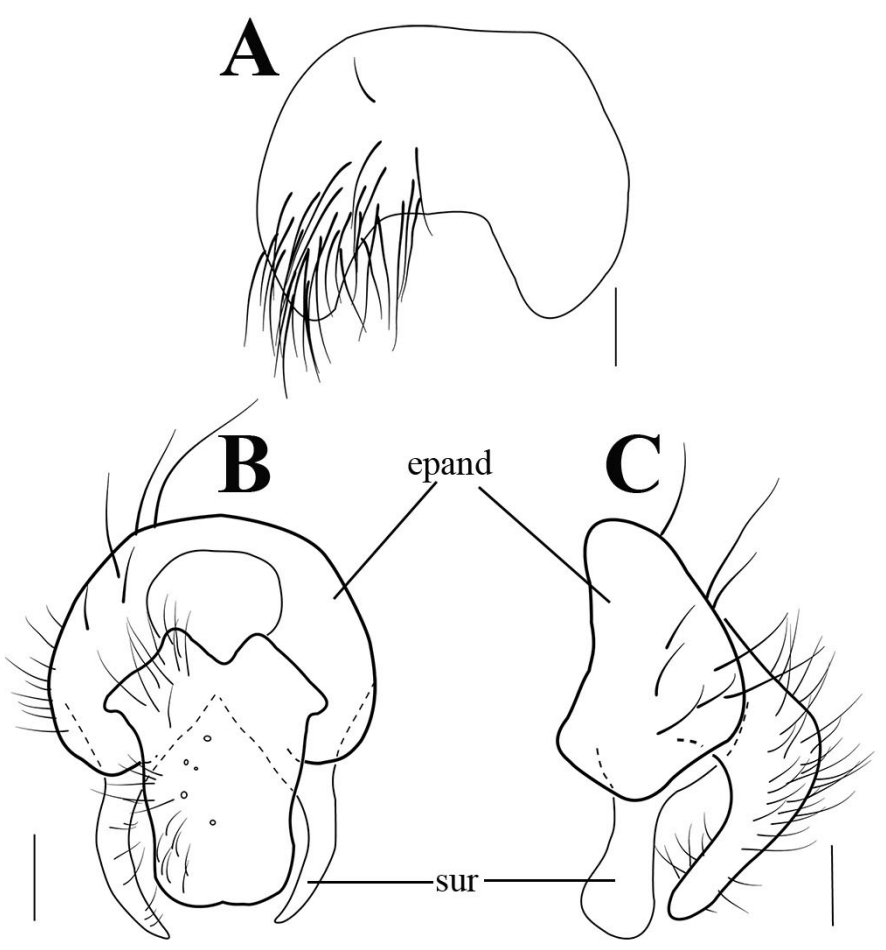

Length. Male: body: $2.8 \mathrm{~mm} \mathrm{~mm}$; wing: $3.0 \mathrm{~mm}$.

Head. Interocular space about one-third of head-width at level of anterior ocellus. Eyes sparsely ciliated. Four pairs of frontal setae of different lengths; one pair of long reclinate orbital setae; ocellar setae long, similar in length to the reclinate orbital. Antennae inserted a little above middle of eyes; flagellomere about 4 times as long as pedicel; arista short pubescent. Cheek narrow. Vibrissa strong and long (Fig. 2b). Proboscis with developed teeth.

Thorax chaetotaxy. acr $s 1+2$; dc $s 1+3$, all long; ial $s 1+2$, the second longer; spal $s$ 1+1; pal $s$; b pprn $s$; npl2; anepst 6 ; a kepst $s 1+1+1$. $b$ sctl $s$ longer than the $s c t l s$ length. Sternite 1 bare.

Legs. Fore femur with 4-8 long $p d$ setae; 2 long basal a setae; row of 11 long $v$ setae and 4 short basal $p v$ setae. Fore tibia with one long median $p$ seta; one $d, p$ preapical seta; one $p v$ apical seta, these three shorts. All pulvilli and claws well developed. Mid femur with 2 long basal a setae; 3 long basal av setae; 4 long sparse $p v$ setae; $p$ with two preapical setae. Mid tibia with a submedian $a$ to $a v$ seta; one $d, p, v$ and $p v$ preapical seta, the $v$ is longer than the other setae. Hind femur with 4 long apical ad setae; one apical $d, p d$ seta and $p d, p v$ with 5 long, and sparse setae, in $a v$ the three basal are less developed. Hind tibia with one long median $p d$, ad seta; one long submedian $d$ seta; one ad, av preapical seta.

Wing. All veins bare, except costal vein.

Abdomen (Fig. 2a and 2e). Elongated. Tergite 1+2 with lateral seta developed, 5 with all median marginal and lateral marginal setae well developed. Sternite 5 triangular, with setae concentrated on apical half (Fig. 7a).

Terminalia (Fig. 7a-d). Surstylus well-developed, longer than cercus, enlarged on lateral view (Fig. 7c). Cercus longer than wide, wider basally than apically, covered with median to long setae (Fig. 7b). Hypandrium moderate to long tubular (Fig. 7d). Phallic complex (Fig. 7d). Phallapodeme enlarged apex; epiphallus long; praegonite

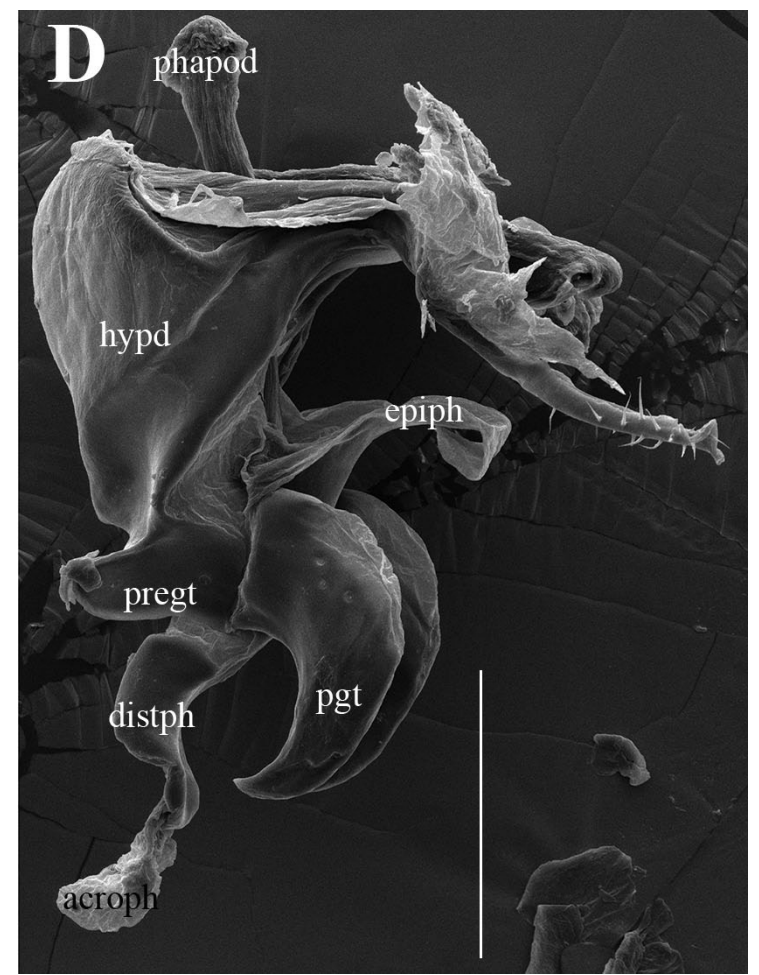

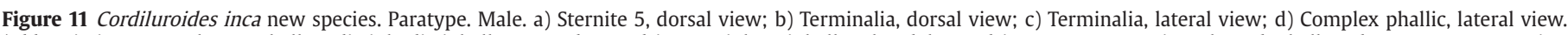

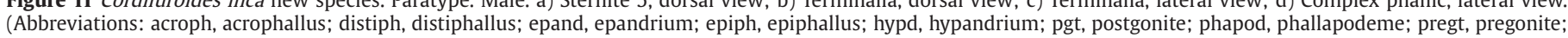
sur, surstylus). Scale bars $0.1 \mathrm{~mm}$. 

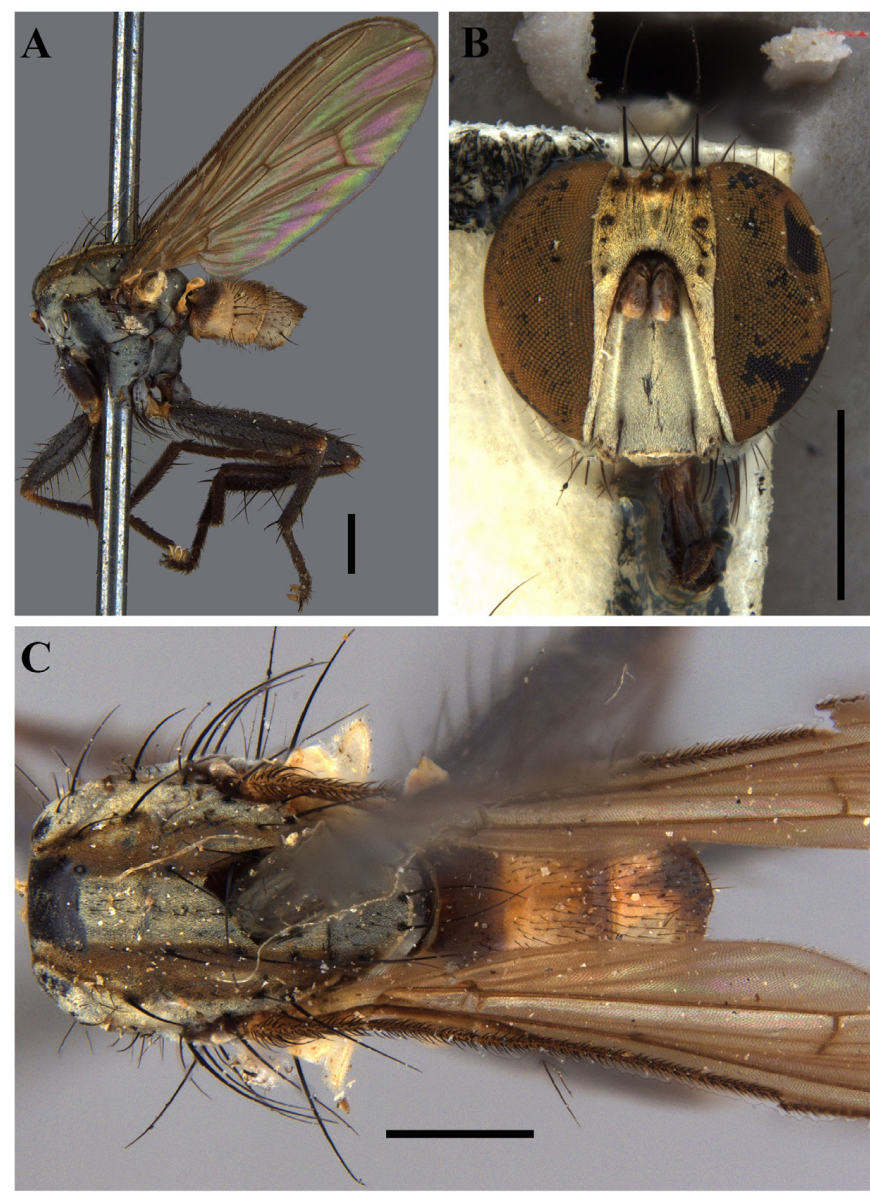

Figure 12 Cordiluroides listrata. Holotype. (MNRJ). Male. a) Habitus, lateral view; b) Head, anterior view; c) Habitus, dorsal view. Scale bars $1 \mathrm{~mm}$.

well developed with a few setulae; postgonite long, curved with a few setulae; distiphallus short and sclerotized, acrophallus membranous.

Female. Similar to male (Fig. 8 a-c).

Terminalia. Ovipositor long with microtrichia along its whole length, tergites fine, cerci long (Fig. 9a-c). Three round spermathecae.

Etymology. The specific epithet, wayqechensis, refers to Wayqecha, the type-locality.

Distribution. PERU, Cuzco: Est. Biol. Wayqecha.

\section{Discussion}

With the three new species described in this study, Cordiluroides comprises 11 species distributed around the Neotropical region, Bolivia, Brazil, Colombia, Costa Rica, Mexico, Saint Vincent, and Peru (Supplementary material-Table S1). Despite the remarkable morphology of the genus, the monophyly of the Cordiluroides is unclear. In the phylogenetic analysis hypothesis to Coenosiini proposed by Couri and Pont (2000), Cordiluroides was placed in a monophyletic clade together with Neodexiopsis Malloch, 1934, based only one synapomorphy: the hind femur with three preapical dorsal setae. However, there is no study available in literature discussing the phylogenetic relationship between species of Cordiluroides.

Describing new species is an important step towards the taxonomic and phylogenetic understanding of a group, furthermore the description of the Cordiluroides albitarsata, $C$. inca, and $C$. wayqechensis, contributes with new morphological characteristics for the genus. Cordiluroides albitarsata presents white setae (beard) in the gena and postgena (Fig. 4c) and fore tarsus with tarsomeres 2-5 flattened and white in male (Fig. 4a). While Cordiluroides inca, and $C$. wayqechensis present the apical scutellar seta reduced, these characteristics enlarging the diagnostic characteristics to species of Cordiluroides. In addition, Cordiluroides albitarsata increasing the knowledge about genus distribution with the first Cordiluroides specie's record to the Brazilian state of Minas Gerais.

\section{Acknowledgements}

To Allen Norrbom (USNM), for the loan of material from Peru used in this study; LSBC-Laboratório de Sistemática e Bioecologia de Coleoptera (UFPR), for specimen images; Centro de Microscopia Eletrônica, Curitiba, Paraná, Brazil, Universidade Federal do Paraná (UFPR), for the SEM images; Viviane R. de Sousa (MNRJ), for the support in the color images; Leonardo Gil (MNRJ) for the access to the material; project SIBBR for the informatization of the biological collections of Museu Nacional (CNPq process number 405588/2015-1) for the help with the auto-montagen equipament. The Conselho Nacional de Desenvolvimento Científico e Tecnológico (CNPq) under the following scholarships and grants: number 140250/2015-8 (JMF), 303414/2018-9 (MSC) and 309873/2016-9 (CJBC). Científica Publicações S/S ME edited the manuscript.

\section{Conflicts of interest}

The authors declare no conflicts of interest.

\section{Author contribution statement}

All authors wrote the paper and contributed equally, all authors critically reviewed the manuscript. All authors approved the final version of this paper.

\section{References}

Albuquerque, D. O., 1954. Fauna do Distrito Federal. XXI: Um gênero e três espécies novas de Coenosiinae (Diptera, Muscidae). Rev. Bras. Biol. 14, 361-369.

Bigot, J. M. F., 1885. Diptères nouveaux ou peu connus. 25e partie. XXXIII. Anthomyzides nouvelles. Ann. Soc. Entomol. Fr. 6, 263-304.

Couri, M. S., de Carvalho, C. J. B., 2002. Part II. Apical groups. In: de Carvalho, C.J.B. (Ed.), Muscidae (Diptera) of the Neotropical Region: Taxonomy. Curitiba. Editora Universidade Federal do Paraná, pp. 133-262.

Couri, M. S., Gonçalves, D., 2002. Descrição de uma nova espécie de Cordiluroides Albuquerque (Diptera, Muscidae, Coenosiinae). Rev. Bras. Entomol. 46, 77-79.

Couri, M. S., Pamplona, D. M., 1992. Cordiluroides Albuquerque, 1954 (Diptera, Muscidae, Coenosiinae): redescrições, notas, sinonímia e chave para as espécies. Rev. Bras. Entomol. 36, 255-262.

Couri, M. S., Pont, A. C., 2000. Cladistic analysis of Coenosiini (Diptera, Muscidae, Coenosiinae). Syst. Entomol. 25, 373-392.

Couri, M. S., de Carvalho, C. J. B., Pont, A. C., 2006. Cordiluroides Albuquerque from Costa Rica: first records, descriptions and taxonomic changes (Diptera, Muscidae, Coenosiinae). Rev. Bras. Entomol. 50, 341-346. https://doi.org/10.1590/S0085-56262006000300003.

Cumming, J. M., Wood, D. M., 2017. Adult morphology and terminology. In: Kirk-Spriggs, A.H., Sinclair, B.J. (Eds.), Manual of Afrotropical Diptera. Vol. 1. SANBI Graphics \& Editing, Pretoria, pp. 89-133 (Suricata 4). 
Löwenberg-Neto, P., de Carvalho, C. J. B., 2013. Muscidae (Insecta: Diptera) of Latin America and the Caribbean: geographic distribution and check-list country. Zootaxa 3650, 1-147. https://doi.org/10.11646/ zootaxa.3650.1.1.

Macquart, J., 1851. Diptères Exotiques nouveaux ou peu connus Suite du 4.e Supplément publié dans les mémoires de 1849 [part]. Mém. Soc. Imp. Sci. Agric. Arts Lille. 1850, 134-294.

Meigen, J. W., 1826. Systematische Beschreibung der Bekannten Europäischen Zweiflügeligen Insekten. Vol. 5. Schultz, Hamm, pp. 412.
Pont, A. C., 1972. Family Muscidae. In: Universidade de São Paulo, A Catalogue of the Diptera of the Americas South of the United States. Vol. 97. Museu de Zoologia, Universidade de São Paulo, São Paulo, 111 pp.

Williston, S. W., 1896. On the Diptera of St. Vincent (West Indies). Trans. R. Entomol. Soc. Lond. 1896, 253-446.

van der Wulp, F. M., 1896. Group Anthomyiinae. In: Godman, F.D., Salvin, O. (Eds.), Biologia Centrali-Americana. Zoologia-Insecta-Diptera, 2 part 132, Taylor \& Francis, London, pp. 321-344. 


\section{Supplementary material}

The following online material is available for this article:

Table S1 - Neotropical Cordiluroides species: Distribution and institution deposition of material type. Syn = Syntypes. BMNH = Natural History Museum, London, United Kingdom. CNC= Canadian National Collection of Insects, Ontario, Canada. MNRJ = Museu Nacional, Universidade Federa do Rio de Janeiro, Rio de Janeiro, Brazil. USNM= National Museum of Natural History, Washington, United States. UMO= Oxford University Museum of Natural History, Oxford, United Kingdom. ZMHU= Museum für Naturkunde, Berlin, Germany. 